Revista Tecné, Episteme y Didaxis: TED. Año 2016, Número Extraordinario. ISSN Impreso: 0121-3814, ISSN web: 2323-0126

Memorias, Séptimo Congreso Internacional sobre Formación de Profesores de Ciencias. 12 al 14 de octubre de 2016, Bogotá

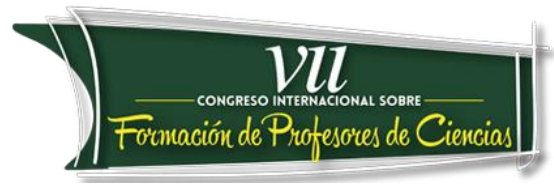

\title{
A pesquisa em tecnologia e os temas que a orbitam: uma análise da produção de publicações em periódicos internacionais
}

Stefoni Böck, Bruno'; Bengio de Albuquerque, Márcia' \& Chrispino, Alvaro

\section{Resumo}

Nossa pesquisa busca identificar as temáticas de pesquisa mais convergentes ao tema tecnologia em periódicos internacionais representativos dos estudos da ciência e tecnologia e, neste trabalho, apresenta o mapeamento do periódico Science, Technology \& Human Valves. Foram coletados 84 artigos sobre tecnologia no periódico que geraram uma rede com 327 palavras-chaves. As palavras-chave foram analisadas em um programa de análise de redes que identificou os termos mais relevantes nas publicações sobre tecnologia da Revista STHV, um importante referencial sobre os estudos da tecnologia que poderá servir como subsídio a ser utilizado pela comunidade docente.

Palavras-chave: CTS, Tecnologia, Redes Sociais, orbital de palavras-chave.

Categoría 2. Trabajos de investigación (en proceso o concluidos).

Línea de trabajo 5. Relaciones entre modelización, argumentación, contextualización, e historia, epistemología y sociología de la ciencia.

\section{Objetivos}

Os estudos da ciência e tecnologia (ECT) surgiram a partir de trabalhos de sociólogos, historiadores e filósofos que atuavam de forma relativamente independente que refutavam o enfoque internalista da ciência e da tecnologia e realizavam interpretações contextuais, críticando a objetividade científica e tecnológica (Cutcliffe, 2004).

\footnotetext{
1 Programa de Pós-graduação em Ciência, Tecnologia e Educação do Centro Federal de Educação Tecnológica Celso Suckow da Fonseca (Cefet/RJ). brunostefoni@gmail.com. marciabengio@gmail.com. alvaro.chrispino@gmail.com
} 
Revista Tecné, Episteme y Didaxis: TED. Año 2016, Número Extraordinario. ISSN Impreso: 0121-3814, ISSN web: 2323-0126

Memorias, Séptimo Congreso Internacional sobre Formación de Profesores de Ciencias. 12 al 14 de octubre de 2016, Bogotá

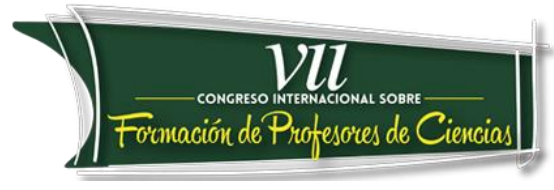

Premebida, Neves \& Almeida (2011) relatam que os ECT são incipientes no Brasil, em contraste com décadas de pesquisa na Europa e Estados Unidos e por isso os trabalhos sobre o tema no país possuem abordagens teóricas limitadas.

O grupo CTS e Educação, do CEFET/RJ, a partir do trabalho de Chrispino, Lima, Albuquerque, Freitas \& Silva (2013), vem se dedicando a mapear de forma sistemática a área CTS no Brasil por meio da metodologia de redes. Neste trabalho, revelam quais as publicações mais citadas em artigos sobre CTS coletadas em periódicos nacionais de relevância na Área de Ensino.

Böck (2015) analisou a relevância da construção social da tecnologia (CST) para as publicações sobre CTS na Área de Ensino no Brasil, tendo verificado que apenas 1,72\% das referências se originavam de autores representantes da CST.

Diante deste resultado, optou-se em iniciar um mapeamento em períodicos internacionais com foco nos estudos da tecnologia (ET), com o objetivo de fornecer às comunidades de pesquisa e docente, um retrato desta área incipiente no Brasil.

Para este trabalho optou-se em mapear a Science, Technology, \& Human Values (Revista STHV), por ser um periódico internacional com mais de 40 anos de publicação que analisa o desenvolvimento da CT com foco nas suas relações com a cultura, política e sociedade (http://sth.sagepub.com).

O objetivo do trabalho é o mapeamento das palavras-chave utilizadas nas publicações sobre tecnologia da Revista STHV, através da metodologia de redes com o intuito de fornecer um retrato da posição da tecnologia no conjunto de artigos deste periódico. Os resultados irão fornecer o conjunto de temáticas que mais convergem à tecnologia na Revista STHV, o que se traduz em um relevante conjunto de temas que poderão ser utilizados por pesquisadores da Área de Ensino na formação de professores e em sequências didáticas.

\section{Marco teórico}

Os ET se caracterizam por serem trabalhos de natureza interdisciplinar, provenientes principalmente da área das ciências humanas nos quais há reflexões sobre a influência que a sociedade exerce no estabelecimento das tecnologias, assim como nas mudanças e consequências sociais ocasionadas pelos sistemas tecnológicos.

Com o objetivo de mapear a produção da área, Böck (2015), a partir de obras que abordavem em CTS os ET, propôs uma classificação para os autores de CST: 
Revista Tecné, Episteme y Didaxis: TED. Año 2016, Número Extraordinario. ISSN Impreso: 0121-3814, ISSN web: 2323-0126

Memorias, Séptimo Congreso Internacional sobre Formación de Profesores de Ciencias. 12 al 14 de octubre de 2016, Bogotá

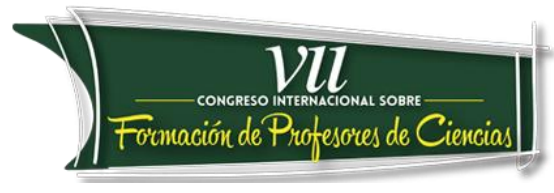

Tecnologia Engenheril, Tecnologia Ética, Tecnologia Humanista e Tecnologia Crítica.

Para abordar a Tecnologia Humanista e compará-la a Tecnologia Crítica, analisaremos um representante de cada corrente: Ortega y Gasset e Hernán Thomas. Ortega y Gasset (1937) demonstra um pessimismo em relação à tecnologia e argumenta que a sociedade tecnológica provocou o surgimento de um homem massa, um homem esvaziado de sentido e de história que seria a maioria conhecida como "todo mundo", a massa dominante que possui poder de decisão e que pode eliminar aqueles que pensam de modo diferente de "todo mundo". Em contra-partida, Thomas, Becerra \& Davy† (2013) refutam o tradicional modelo de desenvolvimento tecnológico e propõem um modelo alternativo baseado na inclusão social, pelo qual diversos atores sociais possuem participação ativa na decisão relativa a processos de inovação que podem ser inibidos ou ativados, conforme a deliberação do grupo de consulta.

\section{Metodologia}

Para mapear as publicações sobre tecnologia, se buscou nas palavras-chave e resumo dos artigos a palavra technology, bem como termos correlatos em inglês relativos a esse universo (artifact, innovation, object, patent, technical, technological e flexões). Desse modo, os resumos e palavras-chave dos artigos foram analisados com o objetivo de identificar nestes os termos relativos à tecnologia, em uma metodologia de análise do conteúdo. Nos casos em que houve dúvidas, os artigos foram analisados em seu inteiro teor. Foram coletados 302 artigos que foram publicados entre 2004 e 2014 na Revista STHV, destes 84 artigos eram sobre tecnologia, conforme a metodologia de busca usada.

Os artigos coletados geraram 327 palavras-chave que foram catalogadas e analisadas através da elaboração de uma rede com 327 vértices e 1269 arestas.

As redes sociais são grafos compostos por um conjunto de vértices e arestas, sendo que os vértices representam a unidade mínima das redes e as arestas correspondem às ligações entre os pares de vértices (Nooy, Mrvar \& Batagelj, 2005). No presente trabalho, as palavras-chave são os vértices e as arestas são as ligações entre elas em um mesmo artigo. O núcleo da rede foi formado pela palavra technology e por termos correlatos já que foi a metodologia usada na coleta dos artigos.

\section{Resultados}


Revista Tecné, Episteme y Didaxis: TED. Año 2016, Número Extraordinario. ISSN Impreso: 0121-3814, ISSN web: 2323-0126

Memorias, Séptimo Congreso Internacional sobre Formación de Profesores de Ciencias. 12 al 14 de octubre de 2016, Bogotá

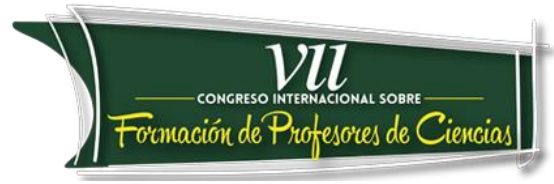

Para a elaboração dos resultados e interpretação das redes de palavras-chave foi utilizado o software Gephi, versão 0.8.2 que é uma plataforma interativa que possibilita visualizar e explorar todos os tipos de redes. As métricas de centralidade utilizadas na análise do orbital foram: a centralidade de proximidade, a centralidade de intermediação e a centralidade do auto-vetor. Quanto mais alta for a medida de centralidade de uma determinada palavra-chave, maior será o seu tamanho na rede. Os resultados das três medidas de centralidade elaboradas são demonstrados na Figura 1, Figura 2 e Figura 3.

Figura 1. Métrica de proximidade da rede de palavras-chave da Revista STHV

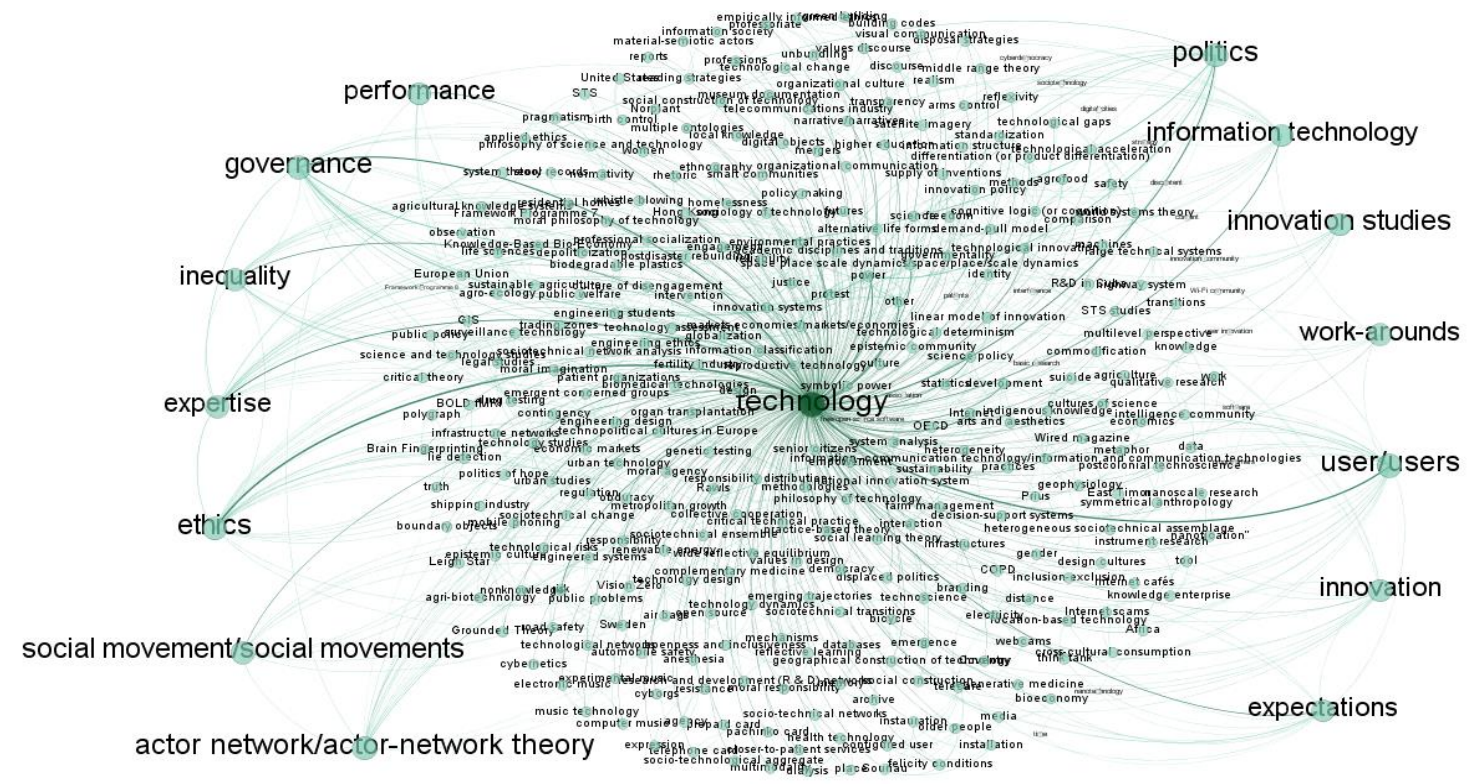

A medida de centralidade de proximidade mede a distância de um vértice em relação aos demais que compõem uma rede (Nooy et al, 2005), isto é, as palavras-chave em destaque são vértices importantes por estarem mais perto de todos os outros vértices da rede, permitindo uma comunicação mais rápida entre os temas que orbitam technology. 
Revista Tecné, Episteme y Didaxis: TED. Año 2016, Número Extraordinario. ISSN Impreso: 0121-3814, ISSN web: 2323-0126

Memorias, Séptimo Congreso Internacional sobre Formación de Profesores de Ciencias. 12 al 14 de octubre de 2016, Bogotá

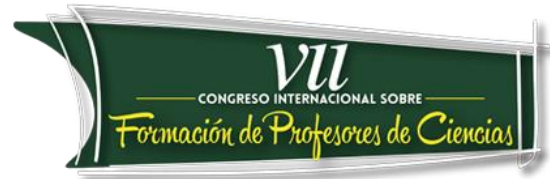

Figura 2. Métrica de intermediação da rede de palavras-chave da Revista STHV

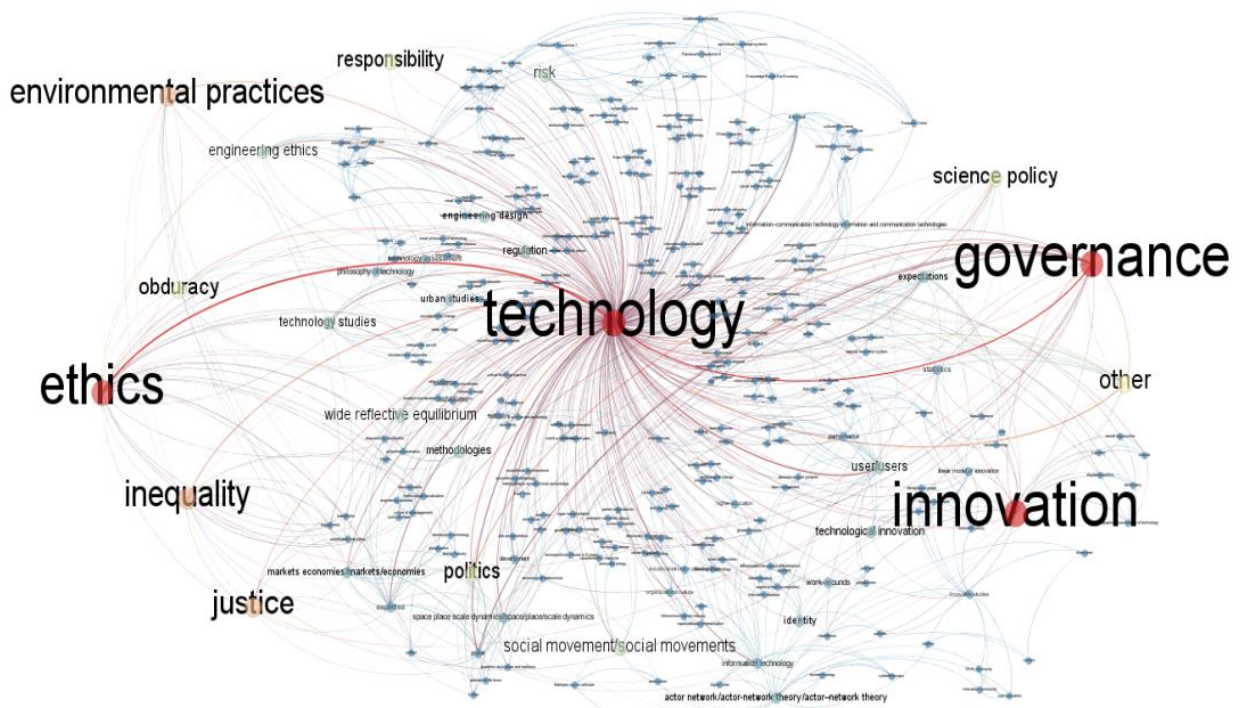

A medida de centralidade de intermediação indica quais vértices são os intermediadores em uma rede social (Nooy et al, 2005), ou seja, quais palavraschave controlam o fluxo de informações no orbital.

Figura 3. Métrica de auto-vetor da rede de palavras-chave da Revista STHV

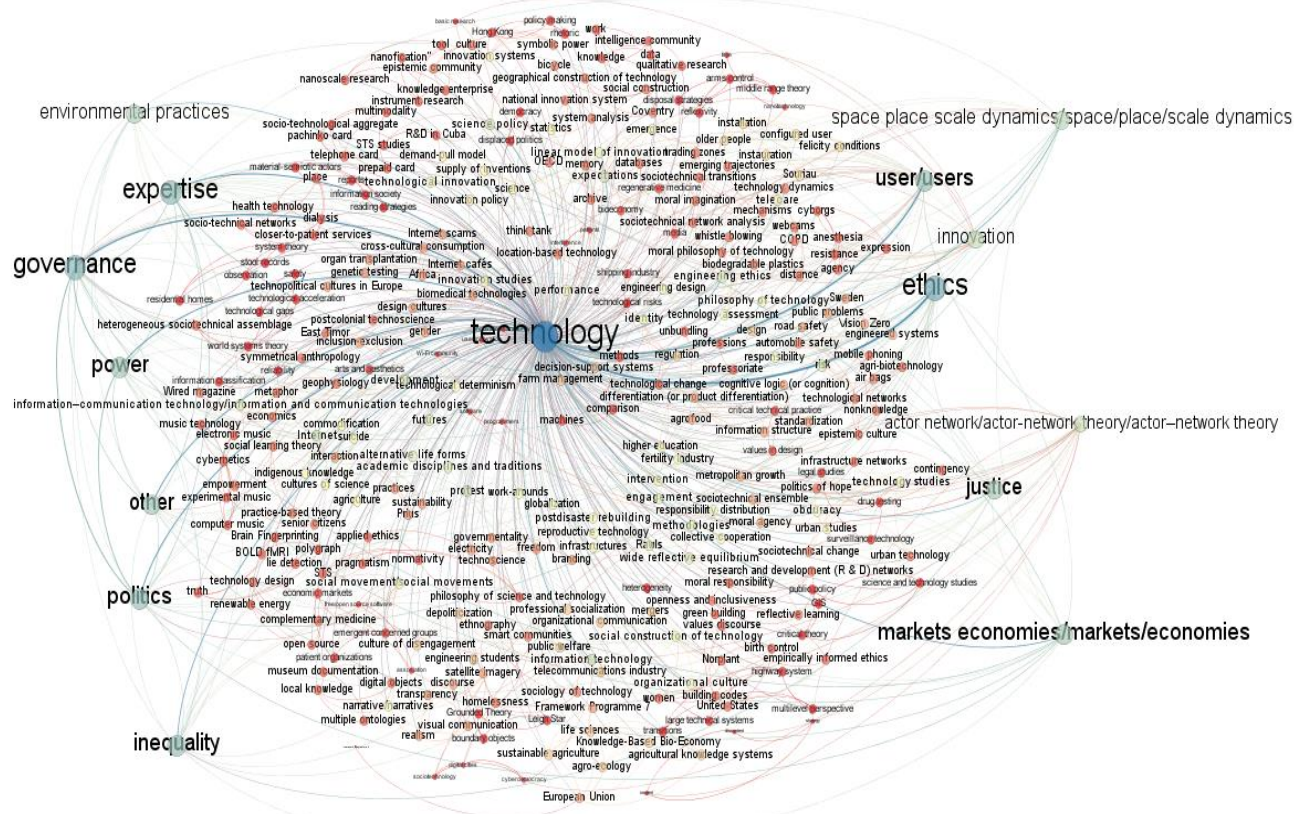


Revista Tecné, Episteme y Didaxis: TED. Año 2016, Número Extraordinario. ISSN Impreso: 0121-3814, ISSN web: 2323-0126

Memorias, Séptimo Congreso Internacional sobre Formación de Profesores de Ciencias. 12 al 14 de octubre de 2016, Bogotá

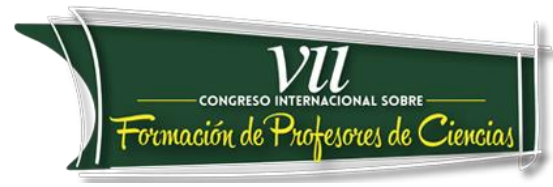

Por fim, a centralidade do auto-vetor mede a qualidade das conexões que os vértices possuem na rede (Nooy et al, 2005), isto quer dizer que uma palavrachave tem alta centralidade se ela está conectada a outras importantes palavras-chave.

Com o intuito de proporcionar uma melhor visualização e possibilitar uma análise holística dos resultados, optamos em apresentar de forma unificada as 10 palavras-chave mais relevantes para cada medida de centralidade, excluindo-se o núcleo (Tabela 1).

Os resultados da Tabela 1 mostram que houve três palavras-chave da rede que aparecem simultaneamente no ranking das três medidas de centralidade: ethics (ética), governance (governança) e politics (política).

Esses três termos denotam um caráter ativista às publicações, o que é compatível com a chamada tradição americana de CTS que se dedica a prevenção e análise das consequências da tecnologia para a sociedade e que possui como uma das principais pautas a inclusão do cidadão na tomada de decisões sobre a tecnologia (Cutcliffe, 2004).

Tabela 1. Palavras-chave da Revista STHV por ranking de centralidade

\begin{tabular}{|c|c|c|c|}
\hline Ranking & proximidade & intermediação & autovetor \\
\hline $1^{\circ}$ & user/users & innovation & ethics \\
\hline 20 & $\begin{array}{l}\text { actor network/ actor- } \\
\text { network }\end{array}$ & governance & governance \\
\hline $3^{\circ}$ & politics & ethics & expertise \\
\hline $4^{\circ}$ & information technology & inequality & politics \\
\hline $5^{\circ}$ & governance & $\begin{array}{l}\text { environmental } \\
\text { practices }\end{array}$ & inequality \\
\hline $6^{\circ}$ & ethics & justice & user/users \\
\hline $7^{\circ}$ & $\begin{array}{l}\text { social movement/social } \\
\text { movements }\end{array}$ & other & power \\
\hline $8^{\circ}$ & innovation studies & obduracy & other \\
\hline
\end{tabular}


Revista Tecné, Episteme y Didaxis: TED. Año 2016, Número Extraordinario. ISSN Impreso: 0121-3814, ISSN web: 2323-0126

Memorias, Séptimo Congreso Internacional sobre Formación de Profesores de Ciencias. 12 al 14 de octubre de 2016, Bogotá

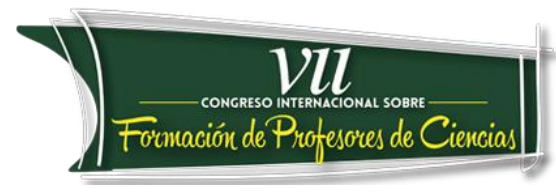

9으

expertise

science policy

markets

economies/markets/economies

$10^{\circ}$

performance

politics

justice

A questão ética da tecnologia vem sendo debatida nos ET que advogam que a ética precisa se modificar continuamente com o intuito de ter capacidade de acompanhar a tecnologia (Mitcham,1989).

Os termos governança e política estão incluídos no âmago da questão ética na medida em que se referem a uma participação efetiva da sociedade na tomada de decisão sobre a tecnologia (Feenberg, 2009).

A abordagem mais ativista das publicações da Revista STHV é corrobarada pela presença como palavras-chave bem classificadas em duas métricas dos termos: inequality (desigualdade), justice (justiça) e user/users (usuário/s) que refletem o caráter negativo das tecnologias que podem ocasionar desigualdades sociais aos seus usuários e em oposição podem contribuir para o alcançe da justiça.

Cabe destacar que o termo actor-network (ator-rede) proveniente da Teoria AtorRede obteve a segunda maior proximidade na rede. A classificação desta teoria como segunda maior proximidade indica que foi utilizada como fundamentação teórica nas publicações da Revista STHV analisadas.

A análise global dos resultados permite levantar alguns aspectos relevantes a área de Ensino. As palavras-chave mais importantes da Revista STHV, identificadas com base nas métricas elaboradas, fornecem uma importante síntese das temáticas que estão sendo pesquisadas em um periódico internacional de tradição na área de ECT, o que fornece aos pesquisadores da área de CTS, incluindo o Ensino, uma lista de temáticas que poderiam ser abordadas em cursos de formação de professores que teriam como objetivo a formação ou atualização dos docentes nos ET.

Tais temáticas, como a ética e a política em tecnologia poderiam também ser transpostas didaticamente com o objetivo de proporcionar aos docentes um relevante conteúdo que poderia ser utilizado em sala de aula.

\section{Conclusões}

Os resultados apresentados demonstraram a diversidade de temas que a Revista STHV com 327 diferentes temas que convergem à pesquisa em tecnologia. Através da análise de redes sociais foi possivel identificar o conjunto de palavras- 
Revista Tecné, Episteme y Didaxis: TED. Año 2016, Número Extraordinario. ISSN Impreso: 0121-3814, ISSN web: 2323-0126

Memorias, Séptimo Congreso Internacional sobre Formación de Profesores de Ciencias. 12 al 14 de octubre de 2016, Bogotá

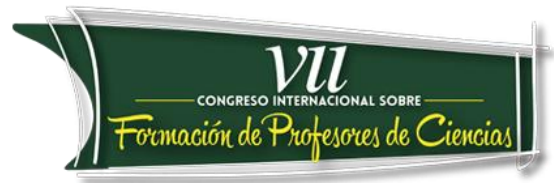

chave mais próximos ao tema tecnologia na Revista STHV e que, portanto, possuem uma maior relavância.

Os temas de maior relevância identificados constituem um importante referencial na área de ET que poderia ser utilizado pela comunidade docente na formação de professores e como material na sala de aula.

Estudos futuros poderão ampliar o mapeamento e incluir outros periódicos representativos dos ET, assim como mapear os autores de maior relevância que tais publicações possuem através da metodologia de redes. Poderão comparar estes resultados com pesquisas similares brasileiras a fim de conhecer convergências e distanciamentos entre as produções internacionais e brasileiras sobre ET. Tais iniciativas em conjunto poderão fomentar a elaboração de um material sobre os ET que poderá ser utilizado na formação de professores, bem como em sequências didáticas sobre o tema.

\section{Referências bibliográficas}

Böck, B. S. (2015). Ciência, Tecnologia e Sociedade e a Construção Social da Tecnologia no Brasil: uma Representação por Análise de Redes Sociais. Dissertação de mestrado, CEFET/RJ, Rio de Janeiro, RJ, Brasil.

Chrispino, A., Lima, L. S., Albuquerque, M. B., Freitas, A. C. C., \& Silva, M. A. F. B. (2013). A Área CTS no Brasil Vista como Rede Social: Onde Aprendemos? Ciência \& Educação, 19(2), 455-479.

Cutcliffe, S. H. (2004). Ideas, máquinas y valores. Barcelona: Anthropos Editorial.

Feenberg, A. (2009). Ciencia, tecnología y democracia: distinciones y conexiones. Scientiae Studia, 7(1), 63-81.

Mitcham, C. (1989). ¿Qué es la filosofía de la tecnología? Barcelona: Anthropos Editorial.

Nooy, W., Mrvar, A., \& Batagelj, V. (2005). Exploratory Social Network Analysis with PAJEK. Cambridge: Cambridge University Press.

Ortega Y Gasset, J. (1937). La Rebelión de las Masas. Madrid: Instantes.

Premebida, A., Neves, F. M., \& Almeida, J. (2011). Estudos sociais em ciência e tecnologia e suas distintas abordagens. Sociologias, 13(26), 22-42.

Thomas, H., Becerra, L., \& Davyt, A. (2013). Repensar el desarrollo y el cambio tecnológico. De la crítica conceptual a la propuesta normativa. Anais da Conferencia Internacional LALICS, Rio de Janeiro, RJ, Brasil, 1. 